\title{
A TERRITORIALIDADE DOS POTIGUARA DE MONTE-MÓR: REGIMES DE MEMÓRIA, COSMOLOGIA E TRADIÇÕES DE CONHECIMENTO
}

\author{
ESTEVÃO MARTINS PALITOT ${ }^{1}$
}

\begin{abstract}
RESUMO
Neste trabalho discutimos a territorialidade do povo indígena potiguara nas terras do antigo aldeamento de Monte-Mór - atuais Terras Indígenas Jacaré de São Domingos e Potiguara de Monte-Mór - localizado nos municípios de Rio Tinto e Marcação, na Paraíba. Estas duas terras indígenas foram objeto de recentes perícias judiciais antropológicas, nas quais um importante conjunto de itens a serem respondidos pelo perito antropólogo versava sobre a tradicionalidade da cultura e da ocupação indígena. Longe de corresponderem aos estereótipos de exotismo e primitividade os Potiguara de Monte-Mór tecem densas e complexas relações ecológicas, econômicas e cosmológicas com os ambientes que constituem as terras indígenas. Para a análise dessas relações mobilizamos diferentes conceitos teóricos à medida que a descrição etnográfica avançava. Nesse sentido, 0 artigo apresenta uma versão resumida do argumento desenvolvido nas duas perícias e aqui organizado em três seções: a) os regimes de memória em disputa; b) as interações cotidianas com os ambientes; c) as tradições de conhecimento que organizam o campo cosmológico potiguara. Sustentamos ao final do artigo que a elaboração de um modelo etnológico sobre a cultura Potiguara com vistas à produção de uma prova pericial deve adotar uma perspectiva dinâmica e processual atenta aos modos diversificados de organização do conhecimento através do qual os grupos domésticos indígenas atuam sobre o mundo.
\end{abstract}

\section{PALAVRAS-ChAVE}

Potiguara; Territorialidade; Regimes de Memória; Campo Cosmológico; Tradições de Conhecimento.

\section{THE TERRITORIALITY OF THE POTIGUARA DE MONTE-MÓR: REGIMES OF MEMORY, COSMOLOGYAND} TRADITIONS OF KNOWLEDGE

\begin{abstract}
In this paper we discuss the territoriality of the Potiguara indigenous people in the lands of the former settlement of Monte-Mór - current Jacaré de São Domingos and Potiguara de Monte-Mór Indigenous Lands located in the municipalities of Rio Tinto and Marcação, in Paraíba. These two indigenous lands have been the subject of recent anthropological judicial investigations, in which an important set of items to be answered by the anthropological expert dealt with the traditionality of indigenous culture and occupation. Far from corresponding to the stereotypes of exoticism and primitiveness, the Potiguara de Monte-Mór weave dense and complex ecological, economic and cosmological relations with the environments that constitute indigenous lands. For the analysis of these relationships, we mobilized different theoretical concepts as the ethnographic description advanced. In this sense, the article presents a summarized version of the argument developed in the two forensics and organized here in three sections: a) the disputed memory regimes; b) daily interactions with environments; c) the traditions of knowledge that organize the potiguara cosmological field. We argue at the end of the article that the development of an ethnological model on the Potiguara culture with a view to producing expert evidence must adopt a dynamic and procedural perspective that is attentive to the diverse ways of organizing knowledge through which indigenous domestic groups act on the world.
\end{abstract}

\section{KEYWORDS}

\footnotetext{
${ }^{1}$ Professor do Departamento de Ciências Sociais e do Programa de Pós-Graduação em Antropologia
} da Universidade Federal da Paraíba - UFPB. 
Potiguara; Territoriality; Memory Regimes; Cosmological Field; Knowledge Traditions.

\title{
LA TERRITORIALITÉ DE LES POTIGUARA DE MONTE-MÓR: RÉGIMES DE MÉMOIRES, COSMOLOGIE ET TRADITIONS DE CONNAISSANCE
}

\begin{abstract}
RÉSUMÈ
Dans cet article, nous discutons de la territorialité des autochtones de Potiguara sur les terres de l'ancienne colonie de Monte-Mór - l'actuel Jacaré de São Domingos et les terres indigènes de Potiguara de Monte-Mór situées dans les municipalités de Rio Tinto et Marcação, à Paraíba. Ces deux terres indigènes ont fait l'objet d'enquêtes judiciaires anthropologiques récentes, au cours desquelles un ensemble important de questions auxquelles l'expert anthropologique doit répondre ont trait à la tradition de la culture et de l'occupation indigènes. Loin de correspondre aux stéréotypes de l'exotisme et de la primitivité, la Potiguara de Monte-Mór tisse des relations écologiques, économiques et cosmologiques denses et complexes avec les milieux qui constituent les terres indigènes. Pour l'analyse de ces relations, nous avons mobilisé différents concepts théoriques au fur et à mesure de l'avancée de la description ethnographique. En ce sens, l'article présente une version résumée de l'argument développé dans les deux forensics et organisé ici en trois sections: a) les régimes de mémoire contestés; b) interactions quotidiennes avec les environnements; c) les traditions du savoir qui organisent le champ cosmologique de la potiguara. Nous soutenons à la fin de l'article que le développement d'un modèle ethnologique sur la culture Potiguara en vue de produire des preuves d'experts doit adopter une perspective dynamique et procédurale attentive aux diverses façons d'organiser les connaissances à travers lesquelles les groupes domestiques autochtones agissent sur le monde.
\end{abstract}

\section{MOTS-CLÉS}

\section{Potiguara; Territorialité; Régimes de mémoire; Champ cosmologique; Traditions de connaissances.}

\section{LA TERRITORIALIDAD DE LOS POTIGUARA DE MONTE-MÓR: RÉGIMEN DE MEMORIA, COSMOLOGIA Y TRADICIONES DE CONOCIMIENTO}

\begin{abstract}
RESUMEN
En este artículo discutimos la territorialidad de los pueblos indígenas Potiguara en las tierras del antiguo asentamiento de Monte-Mór, las tierras indígenas actuales de Jacaré de São Domingos y Potiguara de MonteMór, ubicadas en los municipios de Rio Tinto y Marcação, en Paraíba. Estas dos tierras indígenas han sido objeto de investigaciones judiciales antropológicas recientes, en las cuales un importante conjunto de ítems a ser respondidos por el experto en antropología se ocupó de la tradicionalidad de la cultura y la ocupación indígenas. Lejos de corresponder a los estereotipos de exotismo y primitividad, la Potiguara de Monte-Mór entrelaza relaciones ecológicas, económicas y cosmológicas densas y complejas con los ambientes que constituyen tierras indígenas. Para el análisis de estas relaciones, movilizamos diferentes conceptos teóricos a medida que avanzaba la descripción etnográfica. En este sentido, el artículo presenta una versión resumida del argumento desarrollado en los dos análisis forenses y organizado aquí en tres secciones: a) los regímenes de memoria en disputa; b) interacciones diarias con ambientes; $c$ ) las tradiciones de conocimiento que organizan el campo cosmológico potiguara. Sostenemos al final del artículo que el desarrollo de un modelo etnológico sobre la cultura Potiguara con miras a producir evidencia experta debe adoptar una perspectiva dinámica y procesal que esté atenta a las diversas formas de organizar el conocimiento a través del cual los grupos domésticos indígenas actúan en el mundo.
\end{abstract}

\section{Palabras Clave}

Potiguara; Territorialidad; Regímenes de memoria; Campo cosmológico; Tradiciones del conocimiento. 
Neste artigo, trataremos de uma situação etnográfica específica, a do povo indígena potiguara vinculado às terras do antigo aldeamento de Monte-Mór, localizado no Litoral Norte da Paraíba. Nas últimas quatro décadas (1980-2020) os Potiguara experimentam um conflito social de amplas proporções que envolve disputas em diversos planos. Não é apenas o controle do acesso aos recursos naturais e territoriais que está em questão, mas as próprias interpretações sobre a história deste povo e da região em que vivem que são revistas frente à uma nova configuração social de redefinição das vidas de pessoas e grupos. Esse conflito envolve, de um lado, os grupos industriais e patrimoniais hegemônicos na região (Companhia de Tecidos Rio Tinto e usinas de álcool e açúcar) e, do outro, as famílias indígenas que habitam em diversos ambientes desse território.

Atualmente, os Potiguara vivem em três Terras Indígenas contíguas demarcadas nos municípios de Baía da Traição, Marcação e Rio Tinto. A Terra Indígena (TI) Potiguara possui 21.238 hectares e abrange áreas dos três municípios, a TI Jacaré de São Domingos possui 5.032 hectares e a TI Potiguara de Monte-Mór com 7.487 hectares, ambas localizadas em Marcação e Rio Tinto. Juntas, as três terras abrangem cerca de 33.757 hectares e uma população de 19.525 habitantes (IBGE, 2012), dos quais aproximadamente 14.000 pessoas são indígenas (SIASI, 2013). A TI Potiguara corresponde à Sesmaria dos Índios de São Miguel da Baía da Traição, enquanto as Tls Jacaré de São Domingos e Potiguara de Monte-Mór, correspondem juntas à maior parte da Sesmaria dos Índios de Monte-Mór, antiga aldeia da Preguiça (PALITOT, 2017).

A demarcação dessas terras é recente ${ }^{2}$ e resultante de uma série de conflitos fundiários envolvendo a expansão dos plantios comerciais de cana-de-açúcar que reconfiguraram as relações territoriais e socioeconômicas na região. Em termos históricos, essas demarcações atuaram como um freio em um processo secular de fragmentação e subordinação das famílias indígenas, principalmente nas terras da Sesmaria de Monte-Mór, que foram objeto de um loteamento no século XIX e da implantação do complexo fabril da Companhia de Tecidos Rio Tinto no século XX. As terras de São Miguel da Baía da Traição (TI Potiguara) não foram alvo de loteamento e já em 1932 passaram a ser geridas pelo Serviço de Proteção aos Índios, atualmente Funai.

As mobilizações indígenas pela demarcação das terras produziram um volume considerável de documentação administrativa, acadêmica e judicial ${ }^{3}$ que tem contribuído para a ampliação do conhecimento histórico e etnológico sobre os Potiguara e da qual iremos nos valer aqui para travar a discussão que nos propomos acerca dos modos como os

\footnotetext{
2 A TI Potiguara foi demarcada entre 1981-84, a TI Jacaré de São Domingos em 1988-92 e a TI Potiguara entre 2004-2007.
}

3 A esse respeito ver: BAUMANN, 1981; AZEVEDO, 1986; FIALHO, 1988; BRITO, 1996; PERES, 2004; LIEDCKE, 2007; MARQUES, 2009; SOARES, 2009; PALITOT, 2015; PALITOT; YOGI, 2019. 
Potiguara da Sesmaria de Monte-Mór (TIs Jacaré de São Domingos e Potiguara de MonteMór) tem organizado os seus atuais processos de territorialização (OLIVEIRA, 2004). Рara tanto, tomamos como eixos centrais de análise os temas dos regimes de memória em disputa, das interações cotidianas com os ambientes e das tradições de conhecimento (BARTH, 1987, 2000a) que organizam o campo cosmológico potiguara4.

\section{REGIMES DE MEMÓRIA EM DISPUTA}

A presença indígena no Litoral Norte da Paraíba é marcada por um campo de tensões que envolve os modos como a história e a memória da região são construídas e transmitidas. Três cidades condensam materialmente os tropos discursivos que perpassam essa arena semântica: Baía da Traição, Mamanguape e Rio Tinto. Na primeira, antigos canhões apontados para o mar, as ruínas da igreja de São Miguel e as festividades do dia do índio evocam o evento dos primeiros encontros coloniais, numa atmosfera de antiguidade e primitivismo (LIMA, 1990; PALITOT, 2005; BRAGA, 2019). Em Mamanguape, o casario colonial e as imponentes igrejas testemunham a opulência e as hierarquias da velha sociedade do açúcar (PALITOT, 2005). Rio Tinto, com seu traçado planejado, os prédios de tijolos aparentes e as chaminés da fábrica de tecidos comunica uma visão triunfalista de industrialização, urbanização e modernidade (PALITOT, 2017). Unindo essas imagens díspares paira uma quase assombração de arruinamento sobre as três cidades: na antiga igreja de São Miguel, no casario colonial de Mamanguape e na fábrica de Rio Tinto. Uma verdadeira "ideologia da decadência" (ALMEIDA, 2008b).

Ainda que esse imaginário histórico não seja de todo falso, ele é parcial e lacunar. O primitivismo atribuído à Baía da Traição escamoteia a atuação dos Potiguara ao longo dos séculos; a opulência de Mamanguape, mal consegue disfarçar sua periferia superpovoada com os trabalhadores dos canaviais e em Rio Tinto, o senso de disciplina e velocidade do trabalho industrial faz tempo que adormeceu nos ritmos orgânicos dos aposentados e bichos-preguiça que povoam sua praça central. Nos desvãos dessas imagens, brotam tensões e contradições, disputas e conflitos.

Ocupando um lugar central nessas disputas estão os Potiguara, continuamente objetificados no passado e no exotismo, desconcertam quem espera encontrar neles o espelho do arruinamento e perda. Ao não corresponderem às ideias preconcebidas do que deva ser "um índio" para quem os vê de fora, são logo tachados como "falsos índios" ou "remanescentes", imponderáveis em sua existência atual e complexa, nos meios urbanos, rurais e ribeirinhos. Essas questões se tornam mais agudas quando se associam às disputas

\footnotetext{
${ }^{4}$ A maior parte do material etnográfico para este artigo foi coletado durante a realização de duas perícias judiciais (PALITOT, 2015; PALITOT; YOGI, 2019) e vem somar-se a outros trabalhos mais antigos do autor (PALITOT, 2005; PALITOT; SOUZA JR., 2005).
} 
fundiárias e ganham as páginas dos processos judiciais que contestam a demarcação das terras indígenas.

Assim, não são apenas a dimensão material e produtiva das terras que estão sob controvérsia, mas também suas dimensões simbólicas e representacionais (BOURDIEU, 1989), sendo indissociável do real, as representações que se fazem sobre o real. São os regimes de memória sobre a região e sobre os Potiguara que estão na ordem do dia, em confronto direto. Com a noção de regimes de memória queremos enfatizar justamente "a arquitetura da memória, internamente estruturada e limitada, que tornaria possível a alguém contar histórias sobre o passado" onde são associadas "ações, narrativas e personagens, prescrevendo-lhes formas de construir significados" em contextos assimétricos de dominação e poder (OLIVEIRA, 2011, p.12; ver também FABIAN, 2001).

Notadamente na Sesmaria de Monte-Mór questiona-se a continuidade da presença indígena tomando-se como argumento um regime de memória que atribui ao loteamento da sesmaria e ao empreendimento da Fábrica Rio Tinto a completa diluição da população indígena no processo de modernização industrial do século XX. Em sustentação dessas afirmativas mobiliza-se uma vasta documentação histórica, cartorial e memorialística (GOES, 1963; FERNANDES, 1971; VALE, 2008) que atestaria o desaparecimento de indígenas na região. Eclipsando, inclusive os marcos históricos anteriores ao estabelecimento da fábrica em 1917, como a antiga igreja do aldeamento de Monte-Mór.

Assim, para a população de Rio Tinto que chegou na região para trabalhar na Companhia ${ }^{5}$, a referência histórica original é a instalação da Fábrica Rio Tinto, personificada em um de seus proprietários, o Coronel Frederico Lundgren, a quem se atribui o título de fundador de Rio Tinto (GOES, 1963; FERNANDES, 1971; VALE, 2008; PALITOT, 2017).

As famílias indígenas, por sua vez, sustentam um regime de memória completamente divergente. Enfatizam sua autoctonia e para isso se valem de narrativas familiares, mas também de documentação histórica e de evidências materiais como a imagem de Nossa Senhora dos Prazeres, a padroeira do aldeamento de Monte-Mór com sua igreja do século XVIII.

As narrativas orais sobre a formação do aldeamento de Monte-Mór, articulam memória e história em torno dos signos materiais da Santa e da igreja, que se caracterizam como uma narrativa de origem e sistematizam uma interpretação local sobre o encontro colonial e a condição indígena dos habitantes do lugar. Estas narrativas apresentam variações que dependem de quem as está narrando, como é comum de acontecer com as tradições orais (VANSINA, 1985; ALBERTI, 2004). Entretanto, possuem um fio condutor mínimo que expressa temas como a autoctonia, a mediação da colonização pela intervenção de um poder

\footnotetext{
${ }^{5}$ Neste artigo, todas as expressões locais vêm grafadas em itálico. As aspas referem-se às citações de outros autores ou termos que o autor deseja destacar.
} 
sobrenatural e o estabelecimento de um território especificamente indígena reconhecido oficialmente.

Esse tipo de narrativa é recorrente em outros contextos indígenas no Nordeste do Brasil. E mais além, em outras áreas de colonização antiga na Amazônia e na América Latina (ANDRADE, 1999; ALMEIDA, 2008a; TASSINARI, 2003; PERES, 2004; FIGUEIREDO, 2009; WACHTEL, 1996; TAUSSIG, 1993; WOLF, 2003; VIQUEIRA, 1997). Onde quer que tenham ocorrido aldeamentos missionários reunindo indígenas, conferiu-se especial atenção às mediações proporcionadas pelos entes do panteão católico. Materializados em objetos litúrgicos, mormente na forma de imagens, mas também nos próprios conjuntos arquitetônicos das igrejas, esses símbolos atuaram na reconfiguração das relações sociais nesses espaços coloniais e foram apropriados pelos indígenas como referenciais de pertencimento social e territorial (POMPA, 2003). Nos contextos etnográficos do Nordeste brasileiro vamos encontrar diversos povos indígenas que nutrem especial devoção aos santos padroeiros dos antigos aldeamentos, muitas vezes, realizando festas e celebrações, diferenciando-se do restante da população com quem convivem. Tais práticas, complementam importantes conjuntos narrativos que contam como fundaram-se as relações de predileção e primazia entre os santos e os indígenas (SANTOS, 1997; VIEGAS, 2007; SALOMÃO, 2007; REESINK, 2011; BRASILEIRO, 2004; TROMBONI, 1994; DANTAS, 1997; MOTA, 2008; FIALHO, 1988; NEVES, 2005; ACSELRAD; VILAR; SANDRONI, 2005; PINTO, 1956; BARRETO, 2004; VALLE, 2004).

Entre os Potiguara, a existência de dois aldeamentos missionários - São Miguel da Baía da Traição e Nossa Senhora dos Prazeres de Monte-Mór - também produziu situações e narrativas semelhantes. Com relação à São Miguel, os Potiguara contam sobre a transformação do corpo de um índio falecido na imagem do Santo, após o seu sepultamento. Esse corpo santo teria sido levado para Mamanguape, de onde retornou misteriosamente para o local onde fora encontrado. Tantas vezes foi levado, retornou. Até que construíram a igreja para abrigá-lo, atendendo à vontade manifesta na sua teimosia (PALITOT, 2005; VIEIRA, 2010; BARCELLOS, 2012; BRAGA, 2019). Já em Monte-Mór, as narrativas enfatizam que a Santa foi encontrada pelos $\operatorname{cabocos}^{6}$ numa árvore (geralmente uma jurema), quando voltavam de uma pescaria. Chamaram o padre de Mamanguape e ele a levou embora. No dia seguinte, a imagem sumiu da igreja onde havia sido colocada e voltou para a árvore, caminhando. Prova disso seria a barra do seu vestido suja de lama e com carrapichos grudados. Levada de novo para Mamanguape, tornou a voltar para o tronco. Esse fato se

\footnotetext{
${ }^{6}$ Os Potiguara se identificam a partir dos termos índio, indígena, Potiguara ou caboclo (caboco), que no uso local são praticamente sinônimos. Enquanto os não-indígenas são chamados de brancos, nãoíndios, particulares, sertanejos ou dependentes. Caboclo é um termo na língua tupi que significa "morador da mata" uma denominação bastante antiga, dada a partir do século XVII aos indígenas aldeados e que no contexto colonial queria dizer índio manso, aliado, cristão (PALITOT, 2015).
} 
repetiu até que compreenderam o desejo da Santa: uma capela foi construída para ela naquele lugar. O altar construído exatamente onde ficava a árvore. Ela permaneceu, então. Posteriormente, foi levada definitivamente embora, para Roma, de onde procedeu outra imagem (uma réplica) para ficar em seu lugar. As terras do aldeamento são compreendidas como Patrimônio da Santa, para usufruto dos seus filhos prediletos, os cabocos (FIALHO, 1988; PALITOT, 2005, 2015; VIEIRA, 2010, BARCELLOS, 2012; PAIVA, 2013).

As narrativas sobre a Santa explicitam e comentam a origem do aldeamento da Preguiça, depois Vila de Nossa Senhora dos Prazeres de Monte-Mór. Esta narrativa refere-se não só aos tempos iniciais de fundação do aldeamento, sendo continuamente atualizada, incorporando eventos históricos passados e presentes. Essa atualização reafirma os laços simbólicos e materiais entre um território específico (o Patrimônio da Santa), a população a ele vinculada (os cabocos) e o símbolo que garante essas mesmas relações (a imagem da Santa e a igreja).

Ao analisar os elementos constantes nas diferentes narrativas podemos perceber que a vinculação aos tempos originários se faz através da menção às atividades tradicionais de caça e pesca dos cabocos e à existência de poucas e esparsas casas de palha numa área de mata. Outro símbolo também emerge nesse momento, a jurema, indicando um universo cosmológico mais antigo que o próprio catolicismo. Certas versões mencionam que a Santa foi encontrada num pé de jurema, no qual os cabocos iam rezar e acender velas e nesse momento ela aparecia na forma de uma menina. A jurema é um elemento ubíquo na cosmologia de diversos povos indígenas do Nordeste, centralizando um amplo complexo de referências culturais e religiosas que, a partir dos indígenas, atravessa distintos grupos sociais (TROMBONI, 1994; MOTA, 2008; GRÜNEWALD, 2008). Quando os Potiguara dizem que a igreja foi construída sobre o pé de jurema onde a Santa apareceu, e que, mais precisamente, ele ficava no lugar exato do altar onde a padroeira está entronizada, estão afirmando esse vínculo entre a Santa e o universo cultural indígena ancestral. Estão explicitando o acordo simbólico que foi construído séculos atrás e que permitiu sua adesão ao catolicismo a partir dos seus próprios códigos culturais, garantidos pela predileção que a Santa demonstrou em relação à jurema e aos cabocos.

Nesse sentido, as narrativas nos informam que a igreja da Vila Monte-Mór, marco da articulação entre os mundos colonial e indígena, é a sobreposição de uma nova ordem cósmica sobre aquela pré-existente, representada pelo tronco da jurema localizado em seu interior, mas, sem anular a que estava antes, apenas atualizando-a, mantendo a sacralidade do mesmo lugar. No rito do Toré, os Potiguara entoam músicas que mencionam tanto o universo cultural da jurema quanto a história da Santa Padroeira (PALITOT; SOUZA JR, 2005; VIEIRA, 2010). 
Outro elemento importante a ser destacado é a ideia de Patrimônio da Santa ou Terra da Santa. Essa noção aparece em várias das histórias narradas e menciona as antigas concessões coloniais de patrimônios territoriais para as aldeias missionárias. Durante o período colonial o acesso às terras da colônia estava mediado pela concessão de títulos de sesmaria fornecidos pela Coroa Portuguesa. A Coroa era a única proprietária das terras podendo concedê-las em usufruto para aqueles que quisessem nelas produzir ou que tivessem se destacado na defesa dos interesses da Coroa. Da mesma forma, as aldeias missionárias recebiam uma dotação de terras de acordo com a quantidade de famílias ali reunidas e destinavam-se ao usufruto e sustentação dos índios e suas aldeias. O instituto jurídico das sesmarias perdurou oficialmente até o ano de 1822 e só foi plenamente suplantado com a Lei de Terras de 1850 (BAUMANN, 1981, p. 40-45; CARNEIRO DA CUNHA, 1992, p. 144).

Ainda que a terra da Sesmaria de Monte-Mór tenha sido fracionada em lotes particulares no século XIX, os índios continuaram a conceber esse território como uma unidade mais ampla que se sobrepõe às suas posses familiares e às áreas de uso comum (AZEVEDO, 1986; PALITOT, 2005; VIEIRA, 2010). Cada posse é um espaço de apropriação familiar, passível de ser herdado através das gerações, mas dentro de uma circunscrição maior - o Patrimônio da Santa - que contempla a todas essas posses e as referências enquanto pertencentes a um mesmo território.

Nesse sentido, as terras das sesmarias dos antigos aldeamentos aproximam-se daquelas áreas denominadas por Alfredo Wagner de Almeida como "terras tradicionalmente ocupadas" e que se baseiam em sistemas de "uso comum" da terra e dos recursos naturais por parte de grupos sociais específicos. "Essas modalidades de apropriação não encontram necessariamente correspondência formal no ordenamento jurídico e na ação do estado" mas orientam as relações recíprocas entre grupos de famílias e territórios, que se consolidam no nível das práticas sociais constituindo as áreas denominadas "terras de preto, terras de santo, terras de índio, terras de parentes e terras de ausente, dentre outras" (ALMEIDA, 2008a, p.17-18; ver também ANDRADE, 1999; GODÓı, 1999).

Nas terras de santo, a relação entre as famílias e o território é mediada pela figura mítica do santo padroeiro, que em muitos casos aparece como o titular da propriedade das terras, recebendo pagamentos simbólicos e em espécie das unidades familiares pelo direito de usufruto da terra durante as festas anuais em sua homenagem (ALMEIDA, 2008a, p. 149).

Mesmo que as terras da Sesmaria de Monte-Mór tenham sido fragmentadas em processos sucessivos decorrentes do loteamento do século XIX, da ocupação da Companhia Rio Tinto e das usinas, os Potiguara mantêm viva a noção de que essas terras parceladas e tituladas compõem um universo territorial maior. Esse território tem bases históricas antigas e profundas, remontando ao aldeamento missionário e às suas instituições organizativas (a 
santa, a igreja, o regente, a festa da santa), que são atualizadas continuamente pela categorização étnica da população (os cabocos) que aí vive e se reproduz. Esse modo de vida se dá com a articulação dos usos de áreas apropriadas de modo familiar (os sítios, roçados e lavouras comerciais) e comum (os rios, os tabuleiros, as matas, o manguezal, a maré). Por fim, a área vizinha, da Sesmaria de São Miguel, continuou operando plenamente tanto como aldeamento quanto como terra comum/terra de santo/terra de índio, o que permitiu que fosse a primeira a ser demarcada (TI Potiguara, em 1984), servindo como exemplo político e modelo organizativo para os índios da Sesmaria de Monte-Mór (PALITOT, 2015).

Podemos perceber também que em muitas narrativas as histórias da Santa e do seu Patrimônio aparecem relacionadas com eventos históricos mais recentes como a chegada dos Lundgren, a demarcação da Terra Indígena e mesmo a tentativa de reforma da igreja. Todas essas menções atualizam os sentidos produzidos pela narrativa mítica, adensando sua capacidade explicativa a respeito da origem e da trajetória histórica do grupo indígena e de sua vinculação aquele território culturalmente balizado.

O conjunto de narrativas sobre a Santa e a igreja do aldeamento remarcam assim um regime de memória específico que não se conforma ao registro linear dos autores que escreveram a história da região ou mesmo dos documentos históricos. O regime de memória indígena também não se esgota nesse tema, apresentando outras dimensões fundamentais como aquelas relacionadas às linhagens familiares, locais e modos de habitação, trabalho e lazer, além de uma versão particular sobre a chegada dos Lundgren nas terras de Monte-Mór. Temas que por falta de espaço, não poderão ser tratados nesse artigo.

A memória para ser efetiva necessita ser transmitida através de processos sociais autônomos através dos quais os seus referentes específicos ganhem sentido e coerência e estes podem ser identificados nos domínios da vida cotidiana dos Potiguara. Nos processos de habitar, produzir e consumir é que podemos perceber as relações que são construídas entre pessoas, ambientes, animais, plantas, mortos, instituições, autoridades, santos e encantos e que garantem a reprodução de modos de vida diversificados, mas que ainda assim se reconhecem como variações uns dos outros em suas adaptações urbanas, rurais e ribeirinhas.

\section{COTIDIANO, AMBIENTES E RELAÇõES}

Os Potiguara habitam em um contexto ambiental diversificado e complexo, marcado pela proximidade com o Oceano Atlântico, os manguezais dos estuários dos rios Mamanguape e Camaratuba, as grandes lavouras de cana, a urbanização de cidades pequenas e médias e o afluxo de turistas (CARDOSO; GUIMARÃES, 2012). Assim, a organização social de suas unidades domésticas apresenta grande variação a depender das 
configurações ambientais e socioeconômicas de cada nicho que ocupam. As terras de MonteMór encontram-se numa faixa mais interiorizada do território, às margens do grande estuário do rio Mamanguape, chamado de Maré, e nos vales e tabuleiros dos rios Vermelho, Jacaré e Grupiúna. A urbanização de Rio Tinto e Marcação e a expansão dos canaviais compõem os vetores socioeconômicos mais intensos a direcionar as possibilidades materiais e subjetivas de vida das famílias indígenas.

Podemos identificar nas terras de Monte-Mór três áreas onde concentram-se as habitações indígenas. A primeira delas, fica ao norte e compreende as aldeias de Grupiúna de Cima e Jacaré de São Domingos, às margens dos rios Grupiúna e Jacaré e de nítidas feições rurais. A segunda está localizada na chã entre os rios Mamanguape e Jacaré e é formada pela cidade de Marcação e as aldeias Lagoa Grande, Ybykuara e Três Rios. A terceira, localiza-se também numa área de planalto, nas imediações de Rio Tinto e comporta as aldeias Vila Monte-Mór e Jaraguá, a primeira tendo sido remodelada pela ação dos Lundgren como uma vila operária e a segunda uma povoação de pescadores e agricultores junto ao manguezal do rio Mamanguape (PALITOT, 2015).

Cada uma dessas áreas apresenta aspectos singulares em sua conformação, embora compartilhem também de características mais gerais, como a importância dos quintais enquanto espaços de produção econômica e reprodução social e o acesso a áreas de uso comuns como o mangue, os rios, matas e tabuleiros.

Destaca-se aqui o papel que os quintais desempenham no que toca às atividades produtivas dos núcleos familiares. Cada grupo doméstico ${ }^{7}$ habita uma casa, idealmente próxima das casas de outros parentes próximos (filhos, irmãos, netos, sobrinhos, cunhados) com quem compartilham uma área comum, nem sempre cercada, onde cultivam espécies vegetais diversificadas e criam animais (ARAÚJO, 2017).

A partir dos quintais, as áreas circunstantes são ocupadas com tratos agrícolas ou criatório de animais, comportando também plantios comerciais de tamanhos variados. As áreas de roçado incluem plantios de mandioca, macaxeira, feijão, milho, inhame e fruteiras (manga, coco, caju). Os plantios comerciais dividem-se em dois tipos, os de menor extensão com inhame, frutas (mamão, maracujá, abacaxi) e eucalipto; e os de maior extensão com cana-de-açúcar. As áreas de criatório são mais amplas (a partir de 100 hectares), mas são utilizadas de modo comum por várias famílias, diferente das áreas de plantio que são, até mesmo, individualizadas.

Mesmo naquelas áreas mais urbanizadas como a Vila Monte-Mór ou Marcação, a existência de amplos quintais atrás das casas e o ritmo das atividades agrícolas e pesqueiras

\footnotetext{
${ }^{7}$ Para estudos comparativos sobre a organização social de grupos domésticos indígenas, veja-se: WILK, 1984; MURA; SILVA, 2011.
} 
na Maré singularizam e relativizam a aparência urbana desses núcleos populacionais (PALITOT, 2015; ARAÚJO, 2017).

As mais importantes áreas de uso comum são as matas, os tabuleiros, os rios, o manguezal e o vasto estuário do rio Mamanguape. Constituem reservas de recursos extrativos essenciais ao cotidiano das famílias: além de alimentos e plantas medicinais, recorrem à coleta de varas para plantios, de madeira para construção das casas de taipa, de frutas como mangaba, batiputá e caju e à produção de carvão vegetal.

O manguezal e o rio Mamanguape são os dois elementos mais importantes na ecologia das Terras Indígenas e na vida das comunidades. As atividades de pesca e coleta nesses dois ecossistemas são exercidas por moradores de várias aldeias e não apenas daquelas situadas próximas ao rio.

A interação cotidiana dos Potiguara com os ambientes em que vivem e produzem é marcada por múltiplas relações econômicas, ecológicas e cosmológicas. O acesso às áreas de uso comum para atividades cotidianas é mediado pela interação com os donos desses ambientes: os Encantados. Assim como os Santos Padroeiros São Miguel e Nossa Senhora dos Prazeres tem uma existência singular e exercem domínio sobre as terras dos aldeamentos de Baía da Traição e Monte-Mór, demonstrando preferência pelos seus filhos cabocos. Os demais espaços existentes nas terras indígenas são regidos por seres específicos, que aí habitam. São os Donos desses ambientes, seus Principais. São eles: a Comadre Fulôzinha, o Pai do Mangue, a Mãe-D’Água entre outros seres com quem as pessoas podem se encontrar ao estabelecer relações nos ambientes por eles dominados (SILVA, 2003; VIEIRA, 2010; BARCELLOS, 2012; PAIVA, 2013; PALITOT, 2015).

Importante salientar que boa parte da literatura etnológica evidencia a centralidade de seres não-humanos na organização cosmológica dos povos indígenas e de suas relações com o território (BANDEIRA, 1972; TROMBONI, 1994; ARRUTI, 2004; BARBOSA, 2003; GRÜNEWALD, 2004; ANDRADE, 2008; MURA, 2013; LOPES, 2014; FAULHABER, 1998; TASSINARI, 2003; PERES, 2004, FERREIRA, 2013; MURA, 2006, 2011). Em linhas gerais, os Encantados, Invisiveis, Mestres, Caboclinhos, Caruãnas ou mesmo Bichos são seres espirituais, que podem ou não ter sido seres humanos, que regem determinados espaços ambientais e possuem capacidades sobrenaturais de metamorfose, invisibilidade, adoecimento e cura. As relações com eles são sempre perigosas e delicadas, podendo ocorrer encontros com qualquer pessoa nas mais variadas situações. A comunicação com esses seres exige especialistas rituais com conhecimentos suficientes que os tornem capazes de estabelecer relações de troca e simpatia com esses seres, que tornam-se então seus companheiros ou camaradas $^{8}$. Na maioria dos casos não há, para os indígenas, incompatibilidade entre a

\footnotetext{
${ }^{8}$ Essa percepção cosmológica dos Potiguara guarda grande semelhança com aquela dos GuaraniKaiowá de Mato Grosso do Sul: Cada elemento do universo possui seu dono (járy), este podendo ser
} 
existência desses seres e a aceitação das religiões cristãs predominantes, muitas vezes constituindo-se elaborados sistemas de crenças ecléticos que operam com esses dois níveis de organização do cosmos (MURA, 2013; TASSINARI, 2003; FERREIRA, 2013).

Cada ambiente é dominado por um ser específico. As áreas de mata e tabuleiro são o domínio da Comadre Fulôzinha; o mangue, a Maré e o Fundo do rio Mamanguape são pertencentes ao Pai do Mangue; já os rios, lagoas e o mar são regidos pela Sereia, a Mãe D’Água. São os guardiões dos demais seres viventes nesses ambientes e exigem respeito e sentimentos altruístas por parte de quem se aventura em seus domínios.

Рага os indígenas a existência desses seres não está em causa. Eles são dados empíricos, resultantes da experiência concreta de interação com os ecossistemas locais. Pouco importa se são chamados de mitos ou espíritos, fazem parte da vida cotidiana e devem ser levados em conta pelas pessoas que se aventuram por seus domínios. Alguns Potiguara costumam estabelecer uma diferença entre mito e lenda. Para eles, um mito tem existência real, embora não seja visível ou tangível na maior parte do tempo. Já uma lenda, é uma ficção, algo inventado pela criatividade das pessoas e que não existe de fato. Os Encantados, assim como os Santos, são mitos. Dados da existência concreta, cujas narrativas são comprovações de sua veracidade e das experiências que as pessoas têm com eles. Não são apenas histórias feitas para entreter ou amedrontar.

Seres potencialmente perigosos, os Encantados existem para além da agência humana podendo, no entanto, comunicar-se com determinadas pessoas, por eles escolhidas. A relação com eles reveste-se de cuidados e intimidade, medo e gratidão, respeito e jocosidade. Os Encantados podem flechar as pessoas, botar olhado, causando doenças, fazêlas ficar perdidas, surrá-las e até mesmo, matar, levando o espírito da vítima para o seu Reinado. Contudo, também podem ser generosos e benéficos entregando as caças e os peixes nas mãos de seus parceiros prediletos. Pessoas que tem contato ou devoção com eles sabem relacionar-se com tais seres, thes oferecendo aquilo que gostam: fumo, mel, papa, fitas vermelhas, perfumes. Outras pessoas, especialistas rituais, rezadores ou catimbozeiros, são capazes de uma interação menos desigual com os Encantados, podendo reverter os efeitos de suas flechadas. Da mesma forma, as entidades do panteão cristão têm poderes sobre os Encantados e seus domínios, que são subordinados a Deus (VIEIRA, 2010).

A existência desses seres não é contestada nem mesmo por aqueles Potiguara que são evangélicos. Classificam-nos como entidades malfazejas, oriundas da mitologia bíblica cristã, espíritos maus ou anjos decaídos, que se assenhorearam de domínios específicos na terra: as matas, as águas, o manguezal, etc. Com os quais é possível estabelecer pactos, em forças (mágicas e físicas) e agindo para alcançar seus objetivos (MURA, 2011, p.115). 
troca de almas inocentes. É exatamente a mesma descrição que os demais indígenas fazem, porém, caracterizada como completamente negativa e não apenas como ambígua. Quando perguntamos sobre esse tema em Grupiúna, as mulheres presentes enfatizaram logo essa posição, dizendo: - É o espírito mau! Assim, a crença nos Encantados não é inexistente entre os indígenas evangélicos, mas antes, thes é dado um lugar específico dentro de uma cosmovisão cristã mais estritamente delimitada.

Desse modo, o cotidiano dos Potiguara é preenchido por relações multidirecionais entre seres humanos e não-humanos diversos e que demandam a operacionalização de uma série de saberes e práticas, necessários à boa convivência entre todos os habitantes do cosmos. Organizados a partir de diferentes tradições de conhecimento (BARTH, 1987, 2000a) tais saberes e práticas são uma dimensão fundamental para a compreensão dos modos de vida indígenas e da sua relação com o território.

\section{OPERANDO DENTRO DE UM CAMPO COSMOLÓGICO}

Chamamos de campo cosmológico potiguara um conjunto de conhecimentos e práticas articulados que resultam de um longo processo histórico de elaboração cultural onde tradições de conhecimento indígenas, europeias e afro-brasileiras foram articuladas de modo singular na construção de um referencial prático-simbólico atuante no cotidiano e que Ihes fornece elementos para atuar frente às dinâmicas ambientais, humanas e não-humanas. Trata-se de uma cosmologia em constante processo de produção, aberta às transformações resultantes das ações de todos os seres mutuamente envolvidos (BARTH, 1987).

Assim como em outros contextos indígenas contemporâneos, para os Potiguara a vida social é composta pela interação cosmológica entre diferentes qualidades de seres: vivos, mortos, plantas, animais, Encantados, santos cristãos, malassombros, bruxas, lobisomens, entre outros. Esta é uma interação cotidiana e corriqueira, mas repleta de perigos advindos de mal-entendidos e atitudes moralmente condenáveis de desrespeito, agressão, avareza ou ganância.

São precisos certos cuidados e uma etiqueta de convivência com estes seres que implicam uma grande variedade de atitudes prescritas pela experiência acumulada. Caso seja seguida com observância, essa etiqueta pode angariar a simpatia e as benesses dessas potências. Estabelecer devoção com os Santos, os Encantados ou as almas dos mortos significa alimentá-los com orações e oferendas votivas (velas, fogos, fitas, fumo, papa, etc.) a serem entregues de modo pré-determinado: para os mortos, nas orações diárias ou missas; para os Santos nas novenas e festas; para os Encantos ao entrar na mata ou na Maré. Contrariar a vontade de tais seres ou não cumprir a reciprocidade dos compromissos assumidos pode acarretar sanções, punições ou vinganças cuja intensidade depende do 
tamanho da falta cometida e da natureza da entidade, se mais "selvagem" ou mais "civilizada".

Os desejos e vontades desses seres nunca são previsíveis e podem mesmo interferir fatalmente na vida das pessoas. São potências "selvagens", apenas parcialmente domesticadas e que podem causar grandes danos até em pessoas inocentes. Desse modo, o cosmos para os Potiguara é uma arena de luta e negociação política na qual instâncias terrenas e espirituais equiparam-se continuamente em termos de poder e ação (MURA, 2010; VIEIRA, 2010).

O cotidiano é, pois, preenchido pela necessidade continua de cuidado e atenção com os seres invisíveis. De modo a efetivar essa relação com os melhores resultados possíveis é que atuam os especialistas rituais que são capazes de estabelecer contatos menos desiguais com estes entes, organizando o diálogo e as trocas: para os Santos cristãos são os sacerdotes da igreja e os zeladore(a)s das capelas; para os mortos e os Encantos são os rezadores/curadores, espíritas ou catimbozeiros. Sendo que catimbozeiro é uma categoria de acusação, de modo que o especialista ritual aliado a um determinado grupo doméstico pode ser chamado de rezador, enquanto aquele que the é oposto pode ser chamado de catimbozeiro ou feiticeiro?.

São esses especialistas que mediam ou remediam as relações entre os diversos níveis do cosmos e suas distintas qualidades de seres. Quando algo dá errado e alguém cai doente é aos curadores/rezadores que as pessoas se voltam em busca de reequilibrar as relações que estão desestabilizadas. Geralmente compreendido como um dom, mas também como uma obrigação pesada, a publicização de que alguém tem contato com os seres invisíveis é tratado com bastante reserva, ainda mais se isso se referir a algum membro da própria família.

Os rezadores curam desde mau-olhado (uma agressão que pode ser movida entre pessoas ou entre Encantos e pessoas) até ataques mais sérios como flechadas, pisas e feitiços dependendo das habilidades que possuam. Por estarem continuamente expostos ao meio agressivo da cosmopolítica os rezadores são suscetíveis à loucura ou mortes trágicas como suicídio ou assassinato. Um desses rezadores é lembrado como muito poderoso, capaz de enganar a polícia ou clientes indesejados transformando as margens do rio Grupiúna em um mar caudaloso, fazendo com que estes voltassem antes de chegar em sua casa. Morreu assassinado na própria casa o que provocou a dispersão do seu núcleo familiar (VIEIRA, 2010, p. 86). Outros rezadores de menor poder eram capazes de se invultar, ou seja, esconder-se de

\footnotetext{
${ }^{9}$ Especial atenção tem que ser dada também as parteiras, que são reputadas como conhecedoras de certos mistérios e orações propiciatórias, exatamente por atuarem no espaço liminar do nascimento das pessoas.
} 
perseguidores, encontrar coisas perdidas, curar doenças ou localizar veios de água subterrâneos.

Com os santos católicos as relações ocorrem mediante promessas em momentos de aflição que são pagas com velas, fogos e demais contribuições para a festa daquele Santo. Ocorrendo também episódios de punições severas quando os santos são desrespeitados ou desafiados.

Embora diretamente relacionada à experiência religiosa do grupo a organização cosmológica que descrevemos aqui não se reduz à religião institucionalizada. O que observamos, de um ponto de vista antropológico é como os seres interagem entre si e com o ambiente vivido a partir de práticas e conhecimentos acumulados, que são transmitidos socialmente através de narrativas (mitos) e performances (rituais) oficiados por atores socialmente posicionados em uma economia de saberes distribuída de modo difuso e nãohierárquico. Assim, diferentes tradições de conhecimento são operadas por especialistas rituais e seus pacientes, constituindo uma malha hermenêutica fundamental para a vida cotidiana e os seus dilemas. Essa malha é continuamente atravessada por entes e suas ações e não está circunscrita aos limites étnicos do grupo.

Ao invés de buscarmos uma suposta pureza das práticas indígenas é muito mais lógico percebermos como os Potiguara agem de modo criativo com os materiais culturais disponíveis para a resolução de problemas práticos resultantes das necessidades de interagir com os ambientes e os seres que aí vivem. Atuando com práticas e conhecimentos oriundos da tradição indígena, da tradição cristã (em suas subtradições católica, evangélica e espírita) e da tradição afro-brasileira, cada especialista ritual vai plasmar a sua própria síntese operacional, com vistas a agir no mundo perigoso e tenso da cosmopolítica, curando pessoas, reatando e desfazendo vínculos, agredindo os desafetos e defendendo os seus entes queridos.

O desenho a seguir busca ilustrar os vetores de força através dos quais as diferentes tradições são manejadas, constituindo um campo específico onde práticas e saberes estão em relações constantes de articulação e oposição, dependendo da situação e dos sujeitos que as põem em ação. 


\section{CAMPO COSMÓLOGICO POTIGUARA - FLUXOS CULTURAIS E TRADIÇÕES DE CONHECIMENTO EM CONTÍNUAS RELAÇÕES DE ARTICULAÇÃO E OPOSIÇÃO}

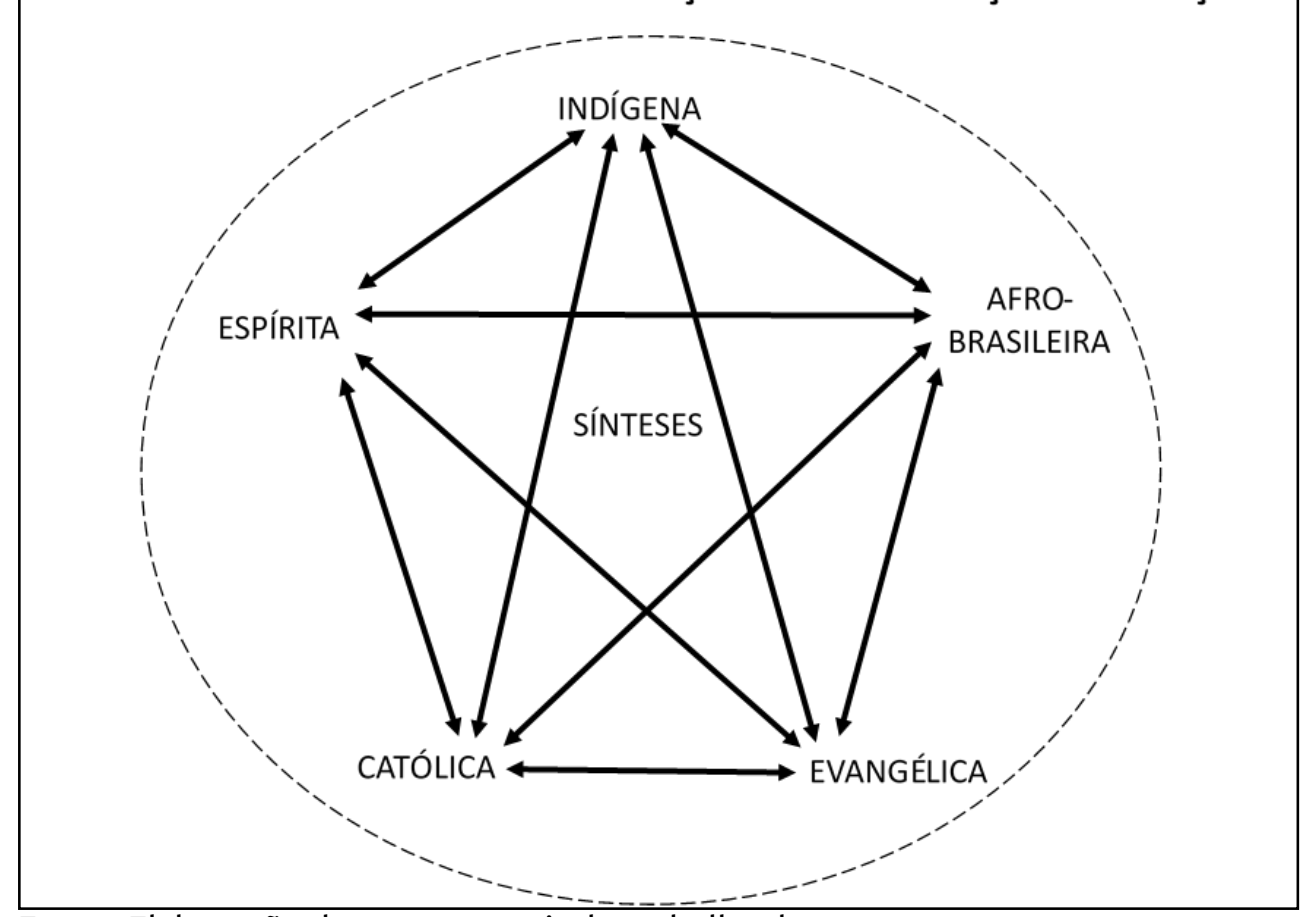

Fonte: Elaboração do autor a partir do trabalho de campo.

As tradições de conhecimento são também territorializadas e remarcadas em diversos lugares de memória (NORA, 1994) constituindo uma geografia própria de lugares, práticas e eventos. Nesse território, ganham destaque uma grande quantidade de lugares de memória, em especial as igrejas sedes dos antigos aldeamentos, que abrigam as imagens dos santos padroeiros e as festas em sua homenagem (Vila São Miguel e Vila Monte-Mór); assim como as capelas das aldeias. Os cemitérios de Mariapitanga, Vila Monte-Mór, Jacaré de São Domingos e Marcação são também importantes referenciais para as aldeias desta Terra Indígena, seja por conterem marcos territoriais significativos, seja por abrigarem os restos mortais de sucessivas gerações de antepassados.

Além desses locais, podemos destacar as ocas e terreiros de toré, espaços de representação étnica e comunitária voltados à realização de eventos e comemorações diretamente alusivas à condição indígena de seus moradores. Inclusive o ritual do toré cumpre importante papel comunicacional nas relações cosmopolíticas dos Potiguara, estabelecendo relações com potências mundanas e extramundanas, dramatizando coletivamente os temas cosmológicos da ancestralidade e da vinculação aos ambientes em que vivem. Nas músicas do toré e em suas performances evocam-se e invocam-se atividades cotidianas (pesca, coleta), eventos históricos (guerras, aldeamentos, festas) e seres espirituais (Reis Canindé, Cabocas de Pena, Tapuia Coronga, santos cristãos, antepassados). O ambiente em que se dança é defumado com grandes cachimbos e bebe-se vinho de jurema, 
em ocasiões mais solenes (PALITOT; SOUZA JR, 2005; VIEIRA, 2010). Do mesmo modo que autoridades não-indígenas podem ser convidadas a entrar na roda do toré e participar do ritual, espíritos podem se manifestar no corpo de pessoas mais sensíveis e exigir participar do ritual, esses são sempre momentos tensos, nos quais descumprir as regras de etiqueta com essas entidades podem gerar sérios mal-entendidos.

Por fim, os ambientes das matas, furnas, tabuleiros, rios, lagoas, nascentes, o manguezal/maré e do mar, com todos os seres neles viventes são também domínios de entes específicos: a Comadre Fulôzinha, a Mãe d'Água e o Pai do Mangue. Não havendo um ponto específico onde eles possam aparecer, pois personificam a experiência cotidiana da interação do ser humano com esses ambientes. O mapa a seguir ilustra cartograficamente a densidade das relações cosmológicas vividas nos ambientes das terras indígenas.

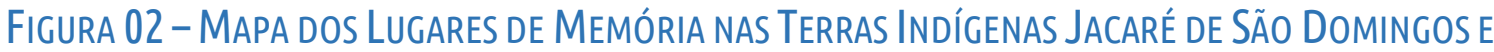 Potiguara de MONTE-Mór}

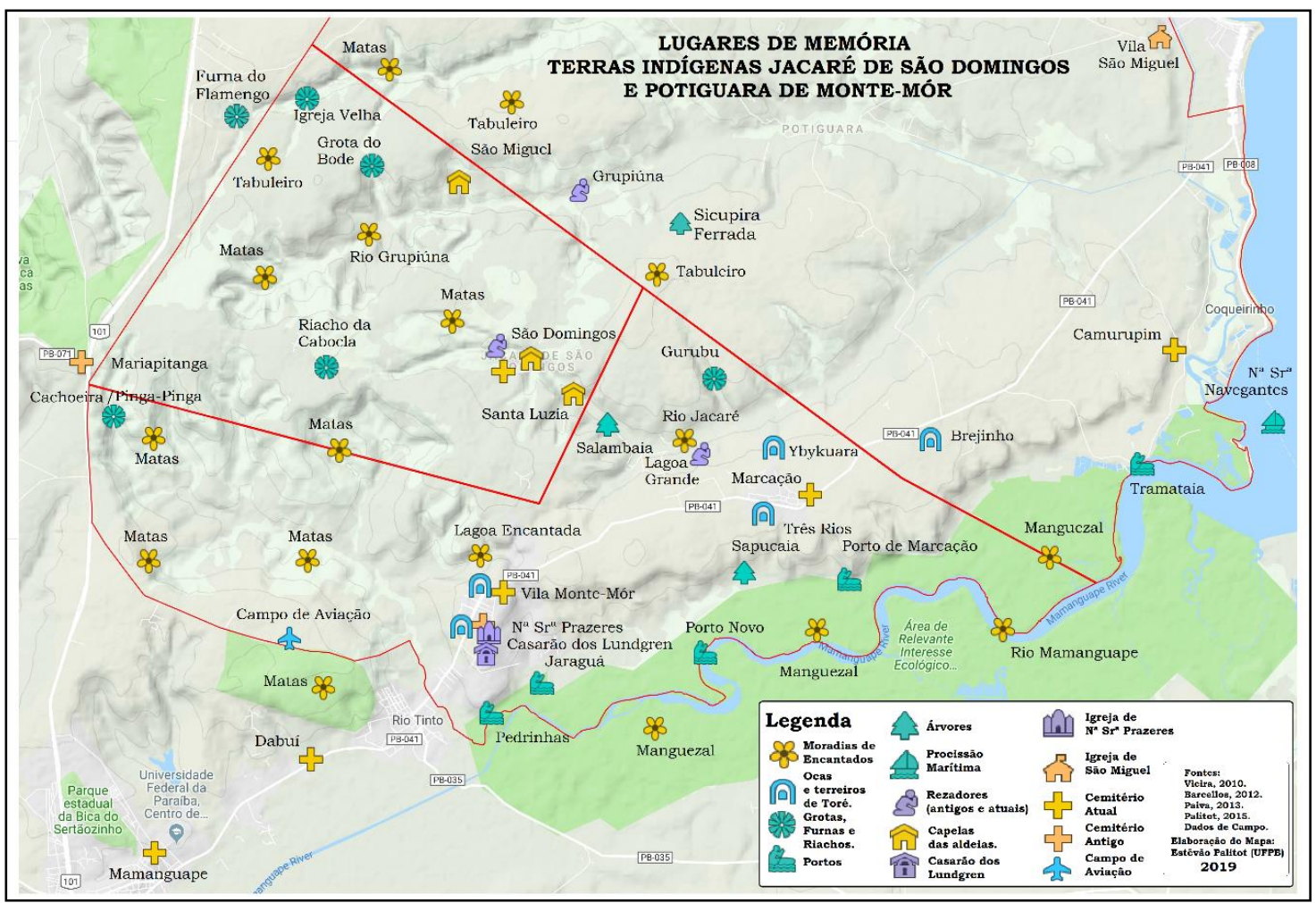

Fonte: Elaboração do autor a partir do trabalho de campo.

\section{CONSIDERAÇÕES FINAIS}

Assim podemos concluir que as relações dos Potiguara com as terras de Monte-Mór ocorrem de modo complexo e holístico, envolvendo não apenas atos de produção econômica, mas de produção e reprodução das relações sociais e cosmológicas a partir de mitos, símbolos, lugares e ritos. Os Potiguara se constituem como uma coletividade diferenciada das demais do seu entorno por compartilharem de um conjunto de memórias e 
símbolos que dizem respeito apenas a eles próprios e que estão profundamente vinculados à noção de sua anterioridade e especificidade na ocupação das terras do aldeamento da Preguiça/Monte-Mór. Isso fica plenamente demonstrado através das narrativas referentes à Nossa Senhora dos Prazeres, padroeira do antigo aldeamento, e que possui forte conotação na definição dos sentidos de pertencimento ao território.

Da mesma forma, as relações cotidianas com o meio ambiente e seus seres são marcadas pela mediação com os Donos das matas, dos mangues e das águas, os Encantados. As interações com os Encantados se revestem de tensões, porém carregadas de intimidade, havendo possibilidades de comunicação e agrados mútuos. As relações assim produzidas, em seus aspectos materiais e simbólicos codificam um modo próprio de reprodução social que também pode ser encontrado nas Terras Indígenas vizinhas, que são coextensões desse mesmo universo étnico e cultural. Tais relações se materializam numa diversidade de lugares de memória disseminados pelas terras indígenas e que tem por finalidade propiciar a recordação de eventos e processos, dos quais o grupo não deseja se esquecer. Por fim, os mitos e os lugares são atualizados e reproduzidos a partir dos ritos, atos performáticos padronizados que estabelecem relações entre os seres habitantes do cosmos, sejam eles indígenas, não-indígenas, plantas, animais, Encantados e Santos. Desde o ato de se deixar fumo para a Comadre Fulôzinha até o de participar nas festas de santos ou nos Torés do dia do índio, todas essas práticas engendram os meios necessários à produção da vida cotidiana e também à constituição de diferenças sociais, produzindo sinais diacríticos (BARTH, 2000b). Estes são operados pelos indígenas de modo gramatical, permitindo a comunicação entre seres habitantes de domínios sociais e cosmológicos distintos.

É através dessa dinâmica de produção contínua da vida, dos sentidos, da comunicação e da diferença que os Potiguara estabelecem seu lugar no mundo e o vinculam a um território que é ao mesmo tempo recurso econômico, patrimônio coletivo e universo simbólico de referência. Assim, não é através de uma lista de traços ou elementos culturais, senão em práticas e sentidos continuamente produzidos e reproduzidos que os Potiguara se constituem como um grupo social singular em interação com outros grupos. Para tanto, a terra, enquanto estrato material e cosmológico, é elemento indispensável à continuidade desses processos que engendram a existência mesma deste povo indígena.

A produção de uma análise antropológica sobre a cultura de um determinado grupo, com vistas à resposta de quesitos judiciais é necessariamente limitada por fatores específicos desse tipo de trabalho em situações periciais - prazos, presença dos assistentes das partes durante o campo, tensões políticas locais, quesitos formulados por leigos em antropologia, etc. Nesse processo, o ofício antropológico baseia-se numa atitude e procedimentos dos mesmos tipos daqueles que descrevemos etnograficamente: uma predisposição aberta ao mundo empírico e sensível, tendo os conceitos como ferramentas 
de interpretação e ação. A composição de um modelo interpretativo possível e inteligível para fora dos limites disciplinares deve estar atenta às dinâmicas e diversidades dos materiais encontrados e às formas plurais com que os diferentes grupos domésticos indígenas organizam as suas tradições de conhecimento. Falar em modelo aqui não significa apresentar uma visão enrijecida do que seria a cultura desse povo indígena, mas antes, fornecer um meio através do qual perceber a contínua produção da vida que se descortina num cotidiano diverso e multideterminado.

\section{REFERÊNCIAS}

ACSELRAD, Maria; VILAR, Gustavo; SANDRONI, Carlos. Torés Pankararu ontem e hoje. In: GRÜNEWALD, Rodrigo. (org.) Toré: regime encantado do índio do Nordeste. Recife. Massangana, 2005. p. 237-250.

ALBERTI, Verena. Ouvir contar. Textos em história oral. Rio de Janeiro: Editora Fundação Getulio Vargas, 2004.

ALMEIDA, Alfredo Wagner Berno de. Terras tradicionalmente ocupadas: terras de quilombo, terras indígenas, babaçuais livres, castanhais do povo, faxinais e fundos de pasto. 2. ed. Manaus: Editora da Universidade do Amazonas, 2008a.

A Ideologia da Decadência: Leitura Antropológica a uma História da Agricultura do Maranhão. $2^{a}$ Edição. Rio de Janeiro: Editora Casa 8 / Fundação Universidade do Amazonas, 2008b.

ANDRADE, Maristela de P. Terra de Índio: terras de uso comum e resistência camponesa. Tese de Doutorado - FFLCH/USP, São Paulo: USP, 1999.

ANDRADE, Ugo M. Memória e Diferença: Os Tumbalalá e as redes de trocas no submédio São Francisco. São Paulo: Humanitas; FAPESP. 2008.

ARAÚJ0, Marianna de Queiroz. Ecologia doméstica e transação de conhecimento entre grupos domésticos Potiguara da Aldeia Jaraguá de Monte-Mór, PB. Dissertação de Mestrado. PPGA/CCHLA/CCAE/UFPB, 2017.

ARRUTI, José Maurício Andion. A árvore Pankararu: fluxos e metáforas da emergência étnica no sertão do São Francisco. In: OLIVEIRA FILHO, João Pacheco de (0rg.). A viagem da volta: etnicidade, política e reelaboração cultural no Nordeste indígena. Rio de Janeiro: Contra Capa Livraria, 2004. p. 231-280.

AZEVEDO, Ana Lúcia Lobato de. 'A terra somo nossa': uma análise de processos políticos na construção da terra potiguara. Rio de Janeiro. Mestrado em Antropologia Social - MN-UFRJ. 1986.

BANDEIRA, Maria de Lourdes. Os Kariris de Mirandela: Um grupo indígena integrado. Estudos Baianos No.6. Salvador: UFBA/Séc de Educação e Cultura do estado da Bahia, 1972.

BARBOSA, Wallace de Deus. Pedra do Encanto: dilemas culturais e disputas políticas entre os Kambiwá e os Pipipã. Rio de Janeiro: Contra Capa Livraria/Laced, 2003. 
BARCELLOS, Lusival Antonio. Práticas educativo-religiosas dos Potiguara da Paraíba. João Pessoa. Ed. UFPB, 2012.

BARRET0, Henyo Trindade. Invenção ou renascimento? Gênese de uma sociedade indígena contemporânea no Nordeste. In: OLIVEIRA, João Pacheco de (org). A Viagem de Volta - Etnicidade, política e reelaboração cultural no Nordeste indígena. Rio de Janeiro: Contra Capa Livraria/LACED, 2004. p. 93-138.

BARTH, Fredrik. Cosmologies in the making. A generative approach to cultural variation in inner New Guinea. Cambridge: Cambridge University Press. 1987

0 guru e 0 iniciador: transações de conhecimento e moldagem da cultura no sudeste da Ásia e na Melanésia. In: LASK, T. (org.). 0 guru, 0 iniciador e outras variações antropológicas. Rio de Janeiro: Contra Capa Livraria, 2000a. p. 141-166.

. Grupos Étnicos e suas Fronteiras. In: LASK, T. (org.). 0 guru, 0 iniciador e outras variações antropológicas. Rio de Janeiro: Contra Capa Livraria. 2000b. p. 25-68.

BAUMANN, Terezinha de Barcellos. Relatório Potiguara. Rio de Janeiro: Fundação Nacional do Índio. 1981.

BOURDIEU, Pierre. A Identidade e a Representação: Elementos para uma Reflexão Crítica sobre a Idéia de Região. In: BOURDIEU, Pierre. 0 Poder Simbólico. Lisboa/Rio de Janeiro, Difel/Bertrand Brasil. 1989 [1980]. p. 107-132.

BRAGA, Emanuel de Oliveira. Histórias indígenas e mitos restauradores: os Potiguara entre santos, festas e ruínas. Tese de Doutorado. PPGA/CFCH/UFPE, 2019.

BRASILEIRO, Sheila. Povo Indígena Kiriri: emergência étnica, conquista territorial e faccionalismo. In: OLIVEIRA, João Pacheco de (org.). A viagem da volta: etnicidade, política e reelaboração cultural no Nordeste indígena. Rio de Janeiro: Contracapa, 2004. p. 281-342.

BRIT0, Maria de Fátima Campelo. Relatório dos estudos de identificação da T. I. Potiguara de MonteMór. Recife, FUNAl, 1996.

CARDOSO, Thiago Mota; GUIMARÃES, Gabriella Casimiro (orgs.). Etnomapeamento dos Potiguara da Paraíba. Brasília. Funai/CGMT/CGETNO/CGGAM. 2012. Disponível em: http://cggamgati.funai.gov.br/files/5314/0735/8761/Etnomapeamento_dos_Potiguara_da_Paraiba.pdf. Acesso em 12 de agosto de 2019.

CUNHA, Manuela Carneiro da. Política Indigenista no século XIX". In: CUNHA, Manuela Carneiro da. (org.). História dos índios no Brasil, $2^{a}$ ed., São Paulo: Cia. Das Letras/ Secretaria Municipal de Cultura/FAPESP, 1992. p. 133-154.

DANTAS, Beatriz Góis. Xokó. Grupo indígena de Sergipe. Aracaju. SEC/NEI, 1997.

FABIAN, Johannes. Ethnology and history. In: FABIAN, Johannes. Anthropology with an Attitud: critical essays. Stanford: Stanford University Press. 2001. p. 70-86. 
FAULHABER, Priscila. 0 Lago dos Espelhos: Etnografia do Saber sobre a Fronteira em Tefé-Amazonas. Belém: Museu Paraense Emílio Goeldi, 1998.

FERNANDES, João Batista. 0 Extinto Rio Tinto. Recife: Imprensa Universitária, 1971.

FERREIRA, Andrey C. Tutela e Resistência Indígena: etnografia e história das relações de poder entre os Terena e o Estado Brasileiro. 1. ed. São Paulo: EDUSP, 2013.

FIALHO, Vânia. Relatório de identificação da Área Indígena Jacaré de São Domingos. Recife. FUNAI, 1988.

FIGUEIRED0, Paulo Roberto Maia. Desequilibrando o convencional: estética e ritual com os Baré do alto rio Negro. Tese de Doutorado em Antropologia Social. Museu Nacional da Universidade Federal do Rio de Janeiro: Rio de Janeiro, 2009.

GODOI, Emília Pietrafesa de. 0 Trabalho da Memória: cotidiano e história no sertão do Piauí. Campinas: Editora da UNICAMP. 1999.

GÓES, Raul de. Um sueco emigra para o Nordeste. Rio de Janeiro: José Olympio, 1963.

GRÜNEWALD, Rodrigo. Etnogênese e "regime de índio" na Serra do Umã. In: OLIVEIRA, João Pacheco de (org). A Viagem de Volta - Etnicidade, política e reelaboração cultural no Nordeste indígena. Rio de Janeiro: Contra Capa Livraria/LACED, 2004. p. 139-174.

. Toré e Jurema: emblemas indígenas no Nordeste do Brasil. Ciência e Cultura, v. 60, n. 4, p. 43$45,2008$.

IBGE. Censo Demográfico 2010. Características gerais dos indígenas. Resultados do universo. IBGE. Rio de Janeiro. 2012.

LIEDCKE, Alice Rubini. Territorialidade e Identidade Potiguara: a atuação do Ministério Público Federal em contextos de lutas pelo reconhecimento dos direitos indígenas no vale do rio Mamanguape, Litoral Norte, PB. (Dissertação de Mestrado em Sociologia) CCHLA/ UFPB: João Pessoa, 2007.

LIMA, José Fernandes de. A lealdade e o heroísmo dos índios Potiguara Pedro Poty. João Pessoa: A União, 1990.

LOPES, Ronaldo Santiago. "A cultura de índio, seu menino, vem de longe aqui": formação histórica e territorialização dos Tremembé/CE. Natal. UFRN. Programa de Pós-Graduação em Antropologia Social. (Dissertação de Mestrado). 2014.

MARQUES, Amanda Christinne Nascimento. Território de Memória e Territorialidades da Vitória dos Potiguara da aldeia Três Rios. João Pessoa. UFPB (Programa de Pós-Graduação em Geografia). Dissertação de mestrado. 2009.

MOTA, Clarice Novaes da. Os Filhos da Jurema na Floresta dos Espíritos. Ritual e cura entre dois grupos indígenas do Nordeste brasileiro. Maceió: Edufal, 2008. 
MURA, Claudia. "Todo mistério tem dono!" Ritual, política e tradição de conhecimento entre os Pankararu. Rio de Janeiro: Contracapa, 2013.

MURA, Fabio. À procura do "bom viver": território, tradição de conhecimento e ecologia doméstica entre os Kaiowa. Tese de doutoramento apresentada ao PPGAS-MUSEU NACIONAL/UFRJ, 2006.

. A trajetória dos chiru na construção da tradição de conhecimento Kaiowa. Mana, v. 16, n. 1, p. 123-150, 2010.

De sujeitos e objetos: um ensaio crítico de Antropologia da técnica e da tecnologia. Horizontes Antropológicos, ano 17, n. 36, jul/dez., p. 95-125, 2011.

MURA, Fabio; DA SILVA, Alexandra Barbosa. Organização doméstica, tradição de conhecimento e jogos identitários. Raízes: Revista de Ciências Sociais e Econômicas, v. 31, n. 1, p. 96-116, 2011.

NEVES, Rita de Cássia Maria. Dramas e Performances: o processo de reelaboração étnica Xukuru nos rituais, festas e conflitos. Tese de Doutorado em Antropologia, Florianópolis: UFSC, 2005.

NORA, Pierre. Entre história e memória: a problemática dos lugares. Revista Projeto História, v. 10, p. 7-28, 1993.

OLIVEIRA, João Pacheco de. Uma Etnologia Dos 'Índios Misturados'? Situação Colonial, Territorialização e Fluxos Culturais. In: OLIVEIRA, João Pacheco de. A Viagem da Volta. Etnicidade, Política e Reelaboração Cultural no Nordeste Indígena. Rio de Janeiro, Contra Capa, 2004. p. 13-42.

OLIVEIRA, João Pacheco de. Apresentação. In: OLIVEIRA, João Pacheco de (Org.). A Presença Indígena no Nordeste: Processos de territorialização, modos de reconhecimento e regimes de memória. Rio de Janeiro: Contra Capa, 2011. p. 09-20.

PAIVA, Eliane Bezerra. Narrativas indígenas: construindo identidades e constituindo-se em fontes de informação. João Pessoa. UFPB, Programa de Pós-Graduação em Linguística (Tese de Doutorado), 2013.

PALITOT, Estêvão Martins. Os Potiguara da Baía da Traição e Monte-Mór: história, etnicidade e cultura. Dissertação de mestrado, PPGS/UFPB. 2005.

PALITOT, Estêvão Martins. OS POTIGUARA DE MONTE-MÓR E A CIDADE DE RIO TINTO: A MOBILIZAÇÃO INDÍGENA COMO REESCRITA DA HISTÓRIA. Revista de Estudos e Investigações Antropológicas, p. 191-215, 2017.

Perícia Antropológica Terra Indígena Potiguara de Monte-Mór. Ação Ordinária nº 0000675 10.2009.4.05.8200 Destilaria Miriri x Funai e outros. ${ }^{\text {a }}$ Vara da Justiça Federal na Paraíba. João Pessoa, Digitado, 2015.

PALITOT, Estêvão Martins; YOGl, Euriko dos Santos. Perícia Antropológica e Agronômica Terra Indígena Jacaré de São Domingos. Ação Ordinária nº 0000366-53.1990.4.05.8200 - Funai x Emílio Celso Acioli de Morais e Outros. $2^{2}$ Vara da Justiça Federal na Paraíba. João Pessoa. Digitado. 2019. 
PALITOT, Estevão Martins; SOUZA JUNIOR, Fernando Barbosa de. Todos os pássaros do céu: o toré Potiguara. In: GRÜNEWALD, Rodrigo de Azeredo (org.). Toré: regime encantado do índio do Nordeste. Recife: Fundaj, Editora Massangana, 2005.

PERES, Sidnei Clemente. Relatório dos novos estudos de identificação e delimitação da Terra Indígena Potiguara de Monte-Mór. Brasília, FUNAl, 2004.

PINTO, Estêvão. Etnologia Brasileira: Fulniô, os últimos tapuias. São Paulo. Cia Editora Nacional, 1956.

POMPA, Maria Cristina. Religião como tradução: missionários, Tupi e "Tapuia" no Brasil colonial. Bauru, EDUSC, 2003.

REESINK, Edwin. 0 coração da aldeia: a ilha, dominação interétnica expropriação territorial histórica e "invisibilidade" dos Kaimbé de Massacará. In: OLIVEIRA, João Pacheco. A presença indígena no Nordeste. Processos de territorialização, modos de reconhecimento e regimes de memória. Rio de Janeiro, ContraCapa, 2011. p. 513-546.

SALOMÃO, Ricardo Dantas. Etnicidade, processos de territorialização e ritual entre os índios Tuxá de Rodelas. Niterói, Universidade Federal Fluminense, Programa de Pós-Graduação em Antropologia Social, Dissertação de Mestrado, 2007.

SANTOS, Ana Flávia Moreira. Do terreno dos caboclos do Sr. João à Terra Indígena Xakriabá: as circunstâncias da formação de um povo, um estudo sobre a construção social de fronteiras. Brasília: UnB, Dissertação de Mestrado, 1997.

SIASI - Sistema de Informação da Atenção à Saúde Indígena. DSEI Potiguara. Dados de 2013. http://dw.saude.gov.br/gsid/servlet/mstrWeb?src=mstrWeb.2048001\&amp;evt=2048001\&amp; share=1\& amp;hiddensections=header\%2Cpath\%2CdockLeft\%2Cfooter\&amp;visMode=0\&amp;currentViewMedia =2\&amp;documentID=0FC0A96611E34C7BBAB90080EFE5381A\&amp;Server=SRVBIPDF03\&amp;Port=0\& amp;Project=DMSIASI 4\& Acesso em 09 de agosto de 2015.

SILVA, Rubens Elias da. Sob o Olhar do Pai do Mangue: A relação homem x natureza e a mediação das narrativas míticas - 0 caso da comunidade da Casa Branca- BayeuX-PB. Dissertação de Mestrado em Sociologia, UFPB - João Pessoa-PB, 2003.

SOARES, Amanda Santos. Direito à terra e a "viagem da volta": processos de construção da Terra Indígena Potiguara de Monte-Mór. João Pessoa, UFPB Programa de Pós-Graduação em Ciências Jurídicas, Dissertação de Mestrado, 2009.

TASSINARI, Antonella M. I. No Bom da Festa: 0 Processo de Construção Cultural das Famílias Karipuna do Amapá. São Paulo: EDUSP. 2003.

TAUSSIG, Michael. Xamanismo, Colonialismo e o Homem Selvagem: Um Estudo sobre o Terror e a Cura. São Paulo, Paz e Terra,1993.

TROMBONI, Marco. "O tronco da Jurema" Ritual e etnicidade entre os povos indígenas do Nordeste o caso Kiriri. Salvador, Dissertação de Mestrado, PPGS/UFBA, 1994. 
VALE, Eltern Campina. Tecendo fios, fazendo história: a atuação operária na cidade-fábrica de Rio Tinto (Paraíba, 1959-1964). Fortaleza, UFC-Programa de Pós-Graduação em História, Dissertação de Mestrado, 2008.

VALLE, Carlos Guilherme Octaviano do. Experiência e semântica entre os Tremembé do Ceará. In: OLIVEIRA, João Pacheco de (org.). A viagem da volta: etnicidade, política e reelaboração cultural no Nordeste indígena. Rio de Janeiro: Contracapa, 2004. p. 281-342.

VANSINA, Jan. Oral Tradition as History. Madison:Wisconsin, 1985.

VIEGAS, Suzana M. Terra Calada: os Tupinambá da Mata Atlântica do sul da Bahia. 7 Letras: Rio de Janeiro, 2007.

VIEIRA, José Glebson. Amigos e competidores: política faccional e feitiçaria nos Potiguara da Paraíba. Tese de doutorado em Antropologia, Universidade de São Paulo, São Paulo, 2010.

. Os Potiguara. Disponível em: www.socioambiental.org.br. Acessado em: 20 de junho de 2011.

VIQUEIRA, Juan Pedro. Indios rebeldes e idólatras. Dos ensayos históricos sobre la rebelión de Cancuc, Chiapas, acaecida en el año de 1712, México. Centro de Investigaciones y Estudios Superiores en Antropología Social, 1997.

WACHTEL, Nathan. Deuses e vampiros: de volta a Chipaya. São Paulo: Edusp, 1996.

WILK, Richard. Households in process: agricultural change and domestic transformation among the Kekchi Maya of Belize. In: NETTING, R. McC; WILK, R.; ARNOLD, E. J. (Org.). Households. Comparative and Historical sutdies of the domestic group. Berkeley: Univesity of California Press, 1984.

WOLF, Eric R. "A Virgem de Guadalupe": um símbolo nacional mexicano. In: FELDMAN-BIANCO, Bela; RIBEIRO, Gustavo Lins (0rg.). Antropologia e Poder: contribuições de Eric Wolf. Brasília/EDUNB, São Paulo/Imprensa Oficial/ Editora Unicamp, 2003. p. 291-306.

Recebido em 5 de fevereiro de 2020. Aprovado em 05 de junho de 2020. 